\title{
Electrochromism of amorphous ruthenium oxide thin films
}

\author{
Se-Hee Lee ${ }^{\mathrm{a}, *}$, Ping Liu ${ }^{\mathrm{a}}$, Hyeonsik M. Cheong ${ }^{\mathrm{b}}$, C. Edwin Tracy ${ }^{\mathrm{a}}$, Satyen K. Deb ${ }^{\mathrm{a}}$ \\ ${ }^{a}$ National Renewable Energy Laboratory, Center for Basic Sciences, 1617 Cole Boulevard, Golden, CO 80401, USA \\ ${ }^{\mathrm{b}}$ Sogang University, Shinsoo-Dong, Seoul 121-742, South Korea
}

\begin{abstract}
We report on the electrochromic behavior of amorphous ruthenium oxide thin films and their electrochemical characteristics for use as counterelectrodes for electrochromic devices. Hydrous ruthenium oxide thin films were prepared by cyclic voltammetry on ITO coated glass substrates from an aqueous ruthenium chloride solution. The cyclic voltammograms of this material show the capacitive behavior including two redox reaction peaks in each cathodic and anodic scan. The ruthenium oxide thin film electrode exhibits a 50\% modulation of optical transmittance at $670 \mathrm{~nm}$ wavelength with capacitor charge/ discharge.
\end{abstract}

(C) 2003 Elsevier B.V. All rights reserved.

PACS: 78.20.Jq

Keywords: Ruthenium oxide; Electrochromic; Counter electrode; Cyclic voltammetry; Capacitive behavior

\section{Introduction}

Growing demands for power sources for transient high-power density have stimulated great interest in electrochemical capacitors in recent years $[1-5]$. An electrochemical capacitor of large specific capacitance (supercapacitor) results when an electrode material with large specific surface area is combined with a material that can be reversibly oxidized or reduced over a wide potential range. For example, the oxides of multivalent metals such as ruthenium and iridium exhibit large faradaic pseudocapacitance [4-6]. Consequently, these materials have often been studied for applications as supercapacitors. In general, conventional electrochromic materials rely upon the insertion

* Corresponding author. Fax: +1-303-3846-531.

E-mail address: slee@nrel.gov (S.-H. Lee). of ionic species and the balancing charge into a host lattice to effect changes in the optical properties of the materials [7-11]. The result is cyclic expansion and contraction of the bulk structure of the electrochromic material during the ion insertion/extraction process. This intercalation process provides a degradation mechanism for the material that can limit the lifetime of the material in the field, and this limitation is inherent in the mechanism of operation of the device [7-14].

In this paper, we report on electrochromic phenomenon induced by supercapacitor charging/discharging in an amorphous hydrous ruthenium oxide thin film electrode. Optical modulation induced by an electrochemical supercapacitor has several advantages in comparison to current electrochromic technologies: (a) since there is no extended ion intercalation into the bulk material, the long-term durability of electrochro- 
mic devices can be significantly improved; (b) since there is little mass transfer process into the bulk material, the response time can be extremely fast (as determined by the capacitor charge/discharge rate).

\section{Experiment}

Hydrous ruthenium oxide thin films were prepared on ITO-coated glass substrates for electrochemical and optical characterization and on polished titanium substrates for Raman scattering measurements. The films were electroplated from the plating solution containing $5 \mathrm{mM} \mathrm{RuCl}{ }_{3} \cdot x \mathrm{H}_{2} \mathrm{O}$. Pt gauze was used as the counter electrode and $\mathrm{Ag} / \mathrm{AgCl}$ as the reference electrode. Cyclic voltammetry (CV) was employed for the electrolysis procedure and performed at room temperature between 0 and $1000 \mathrm{mV}$ at a scan rate of $50 \mathrm{mV} \mathrm{s}^{-1}$. Electrochemical behavior of the ruthenium oxide film electrodes was examined using cyclic voltammetry in a $0.5 \mathrm{M} \mathrm{H}_{2} \mathrm{SO}_{4}$ electrolyte solution.

The Raman spectra were taken in the quasi-backscattering geometry using $100 \mathrm{~mW}$ of the $514.5 \mathrm{~nm}$ line of an Ar ion laser, focused to a line of 5 $\mathrm{mm} \times 100 \mu \mathrm{m}$, as the excitation source. The signal was dispersed by a Spex $0.6 \mathrm{~m}$ triple spectrometer and detected with a liquid-nitrogen-cooled high-resolution charge-coupled-device detector array. Both the spectral resolution and the accuracy in the Raman shift are estimated to be $\sim 2 \mathrm{~cm}^{-1}$.

\section{Results and discussion}

Fig. 1 shows the typical growth behavior of an amorphous hydrous ruthenium oxide thin film deposited onto ITO coated glass substrates in a solution of 5 $\mathrm{mM} \mathrm{RuCl}{ }_{3} \cdot x \mathrm{H}_{2} \mathrm{O}$. As the number of $\mathrm{CV}$ cycles increases, the voltammetric current also increases and saturates at around 50 cycles. The $\mathrm{V}_{2} \mathrm{O}_{5}$ film thickness after 50 cycles was approximately $200 \mathrm{~nm}$. The results from thermogravimetric analyses indicate that the as-deposited a- $\mathrm{RuO}_{2} \cdot x \mathrm{H}_{2} \mathrm{O}$ thin film contains approximately two water molecules per mole of $\mathrm{RuO}_{2}$, which is consistent with the previous reports [4]. In contrary to previous reports [15], however, ruthenium oxide growth was greatly inhibited in the

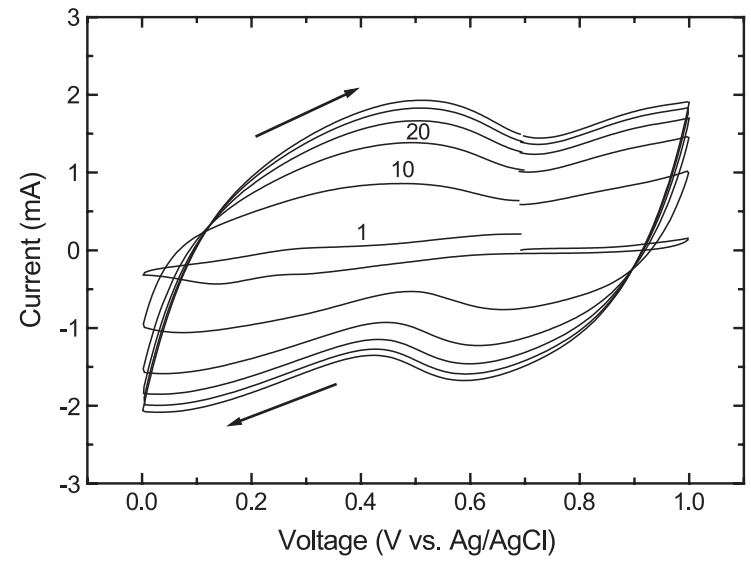

Fig. 1. Growth behavior of an amorphous hydrous ruthenium oxide thin film electrochemically deposited onto ITO coated glass substrates in a solution of $5 \mathrm{mM} \mathrm{RuCl} 3 \cdot x \mathrm{H}_{2} \mathrm{O}$. Cyclic voltammetry was performed at room temperature at a scan rate of $50 \mathrm{mV} \mathrm{s}^{-1}$ between 0.0 and $1.0 \mathrm{~V}$ vs. an $\mathrm{Ag} / \mathrm{AgCl}$ reference electrode.

presence of either $\mathrm{HCl}$ or the supporting electrolyte (e.g. $\mathrm{KCl}$ ). Our amorphous hydrous ruthenium oxide films could only be successfully grown when a simple plating solution containing ruthenium chloride (and devoid of $\mathrm{HCl}$ and supporting electrolyte) was used. Even so, when the concentration of ruthenium chloride exceeds $0.5 \mathrm{M}$ (resulting in a relatively strong acidic solution of $\mathrm{pH}<2$ ), no films could be obtained. A detailed deposition mechanism is currently under investigation to elucidate this phenomenon. Fig. 2 shows the cyclic voltammogram of the as-deposited ruthenium oxide film electrodes in a potential range of $0.0-1.0$ vs. $\mathrm{Ag} / \mathrm{AgCl}$. This cyclic voltammogram shows the typical capacitive behavior of ruthenium oxide electrode including two redox reaction peaks in each cathodic and anodic scans.

With constant charge/discharge current, the in-situ optical transmittance variation of the as-deposited $\mathrm{RuO}_{2} \cdot x \mathrm{H}_{2} \mathrm{O}$ film electrode was monitored with a laser diode at $670 \mathrm{~nm}$ wavelength. The $670-\mathrm{nm}$ transmittance was recorded as a function of time using a computer-controlled potentiostat. Fig. 3 shows the insitu optical modulation vs. time with capacitor charge/ discharge. The relative optical modulation is defined as $\left(T_{\mathrm{b}}-T_{\mathrm{c}}\right) \times 100 / T_{\mathrm{b}}$, where $T_{\mathrm{b}}$ and $T_{\mathrm{c}}$ are the bleached and colored transmittance, respectively. The $\mathrm{RuO}_{2} \cdot x \mathrm{H}_{2} \mathrm{O}$ film electrode successfully exhibited $50 \%$ modulation of optical transmittance with capac- 


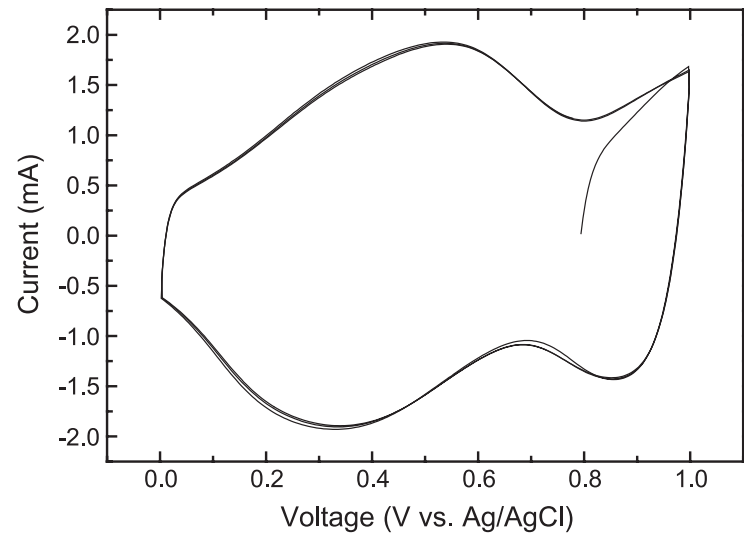

Fig. 2. Cyclic voltammogram of $\mathrm{RuO}_{2} \cdot x \mathrm{H}_{2} \mathrm{O}$ thin film electrode in $0.5 \mathrm{M} \cdot \mathrm{H}_{2} \mathrm{SO}_{4}$ at a scan rate of $20 \mathrm{mV} / \mathrm{s}$. The reference electrode is a $\mathrm{Ag} / \mathrm{AgCl}$.

itor charge/discharge at a current density of $0.5 \mathrm{~mA} /$ $\mathrm{cm}^{2}$. Even at a current density of $10 \mathrm{~mA} / \mathrm{cm}^{2}$, the electrode exhibits around $45 \%$ optical modulation (indicating the fast response time of this electrode as would be expected from an electrochemical capacitor). It is of great interest to notice that the $\mathrm{RuO}_{2} \cdot x \mathrm{H}_{2} \mathrm{O}$ electrode changes color in an anodic coloring fashion. In other word, the film bleaches with discharge (proton insertion) in contrast to the conventional electrochromic $\mathrm{WO}_{3}$ material that colors with proton insertion $[7,8]$. In this respect, the anodic coloring ruthenium oxide thin films can be used as a counter electrode in complementary-type electrochro-

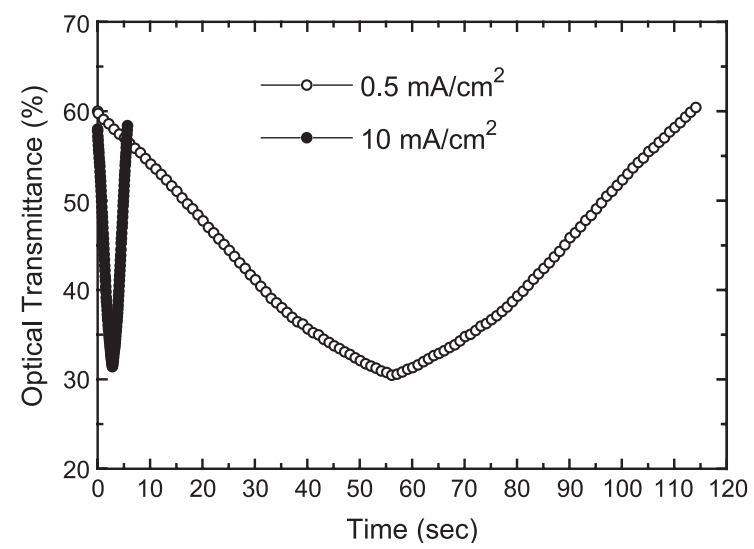

Fig. 3. In-situ relative optical transmittance variation at $670 \mathrm{~nm}$ wavelength. The charge/discharge current densities are $0.5 \mathrm{~mA} / \mathrm{cm}^{2}$ (open circle) and $10 \mathrm{~mA} / \mathrm{cm}^{2}$ (solid circle). mic devices. Fig. 4 shows the optical response of the as-deposited $\mathrm{RuO}_{2} \cdot x \mathrm{H}_{2} \mathrm{O}$ film electrode over the full wavelength range. About $50 \%$ transmittance modulation was obtained over the visible and near IR wavelength range.

Fig. 5 shows the $\mathrm{CV}$ curves of $\mathrm{RuO}_{2} \cdot x \mathrm{H}_{2} \mathrm{O}$ thin film electrodes annealed at different temperatures in a $0.5 \mathrm{M} \mathrm{H}_{2} \mathrm{SO}_{4}$ electrolyte with a voltage scan rate of 10 $\mathrm{mV} / \mathrm{s}$ in a potential range of $0.0-1.0 \mathrm{vs} . \mathrm{Ag} / \mathrm{AgCl}$. The CV curve of the as-deposited ruthenium oxide film electrode (Fig. 2a) exhibits a capacitive behavior and also two redox reaction peaks in each cathodic and anodic scan. As the annealing temperature increases (see Fig. 2a-d sequentially), the CV curves become featureless and more like a rectangular shape indicating voltage independence of the capacitor electrode (which is the main characteristic of a pure capacitor).

Fig. 6 shows the optical modulation at $670 \mathrm{~nm}$ wavelength of the $\mathrm{RuO}_{2} \cdot x \mathrm{H}_{2} \mathrm{O}$ thin film electrodes annealed at different temperatures. As the annealing temperature is increased, the degree of optical modulation decreases and no optical modulation is observed at $300{ }^{\circ} \mathrm{C}$. Based on these two experimental results (CV curves in Fig. 3 and optical modulations in Fig. 6 ), one can readily deduce that the optical response of the $\mathrm{RuO}_{2} \cdot x \mathrm{H}_{2} \mathrm{O}$ thin film electrodes is strongly associated with two redox reaction peaks in each cathodic and anodic scan; the two peak currents decrease as the annealing temperature increases.

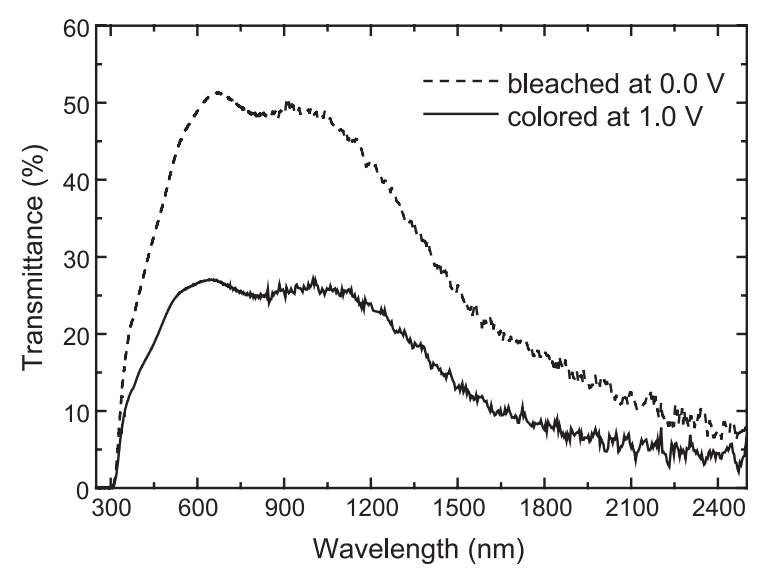

Fig. 4. The transmittance spectra of a $\mathrm{RuO}_{2} \cdot x \mathrm{H}_{2} \mathrm{O}$ thin film. The film is colored at $1.0 \mathrm{~V}$ and bleached at $0.0 \mathrm{~V}$ vs. $\mathrm{Ag} / \mathrm{AgCl}$. 

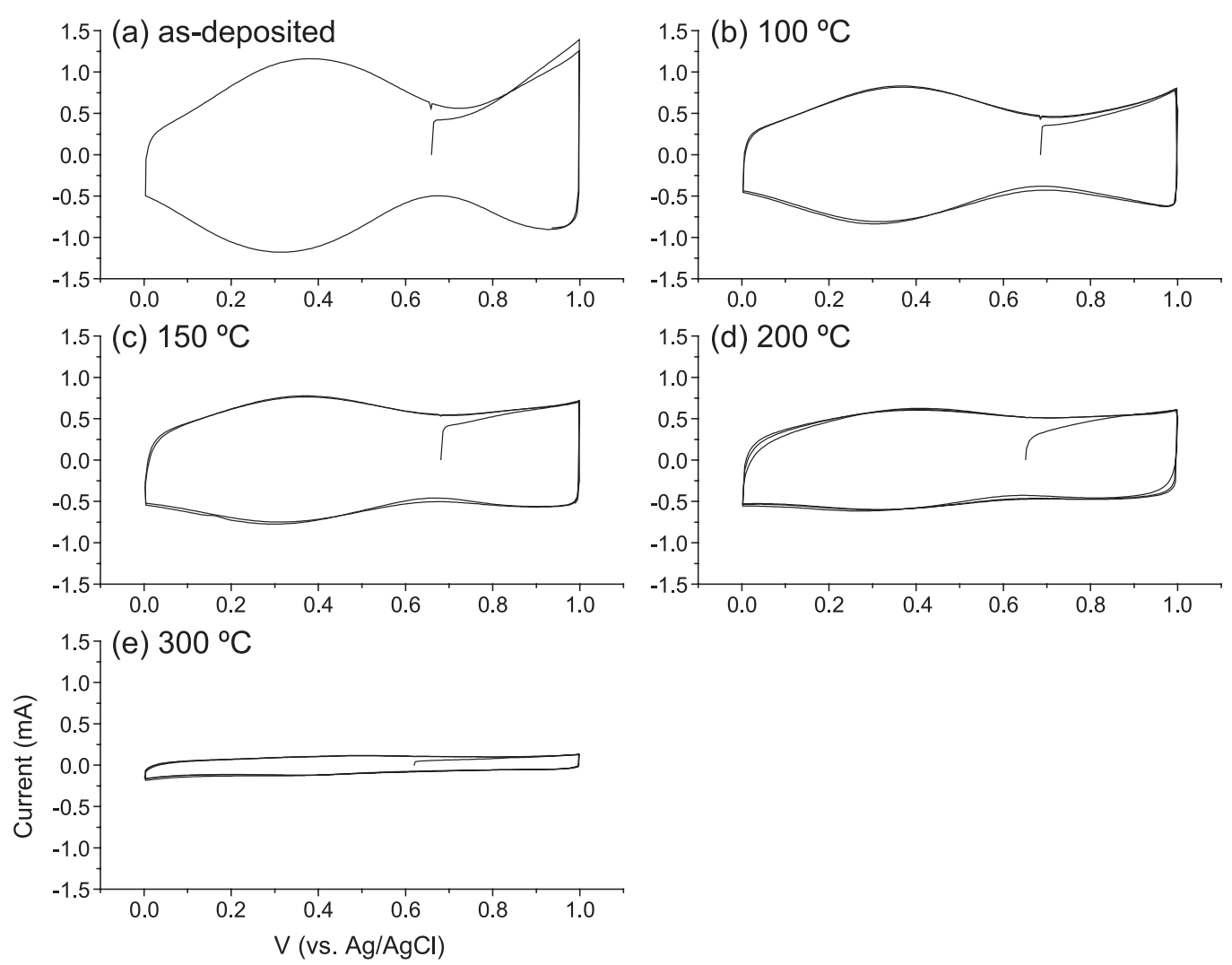

Fig. 5. Cyclic voltammograms of $\mathrm{RuO}_{2} \cdot x \mathrm{H}_{2} \mathrm{O}$ thin film electrodes annealed at different temperatures of $25,100,150,200$ and $300{ }^{\circ} \mathrm{C}$. The cyclic voltammetry was carried out in a $0.5 \mathrm{M} \mathrm{H}_{2} \mathrm{SO}_{4}$ electrolyte with a voltage scan rate of $10 \mathrm{mV} / \mathrm{s}$ in a potential range of $0.0-1.0 \mathrm{~V}$ vs. $\mathrm{Ag} / \mathrm{AgCl}$.

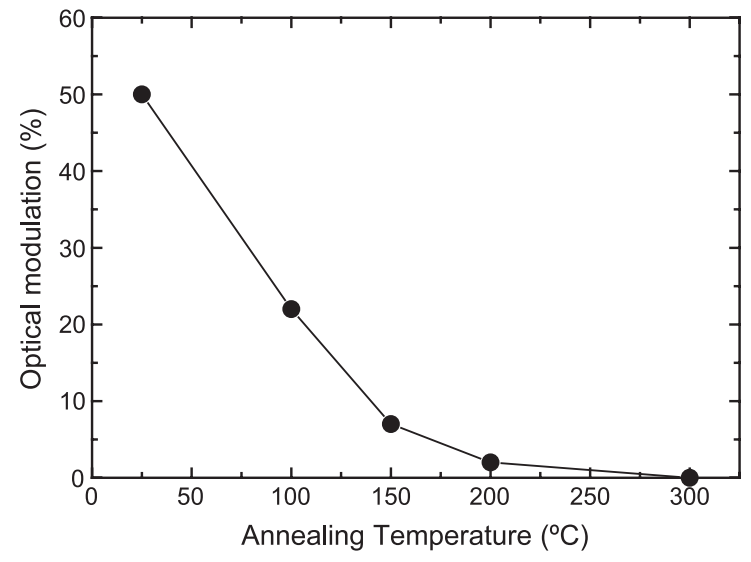

Fig. 6. Relative optical modulation at $670 \mathrm{~nm}$ wavelength of $\mathrm{RuO}_{2} \cdot x \mathrm{H}_{2} \mathrm{O}$ thin film electrodes annealed at different temperatures of $25,100,150,200$ and $300{ }^{\circ} \mathrm{C}$.
Raman spectroscopic measurements were performed on the $\mathrm{RuO}_{2} \cdot \mathrm{xH}_{2} \mathrm{O}$ thin films as shown in Fig. 7, in order to examine the micro-structural changes with increasing annealing temperature. The spectrum of the as-deposited $\mathrm{RuO}_{2} \cdot x \mathrm{H}_{2} \mathrm{O}$ thin film (a) shows a broad peak at $450 \mathrm{~cm}^{-1}$ which has been assigned to hydrated $\mathrm{RuO}_{2}$ [16]. In addition, there is a weaker, broader peak at $700 \mathrm{~cm}^{-1}$, which has not yet been identified. As the annealing temperature is raised, the intensity of the Raman peak at $450 \mathrm{~cm}^{-1}$ decreases and finally becomes indifferent at $300{ }^{\circ} \mathrm{C}$. At $300{ }^{\circ} \mathrm{C}$ the film exhibits sharp crystalline features of the rutile tetragonal phase of $\mathrm{RuO}_{2}$. The three major Raman bands, namely $\mathrm{E}_{\mathrm{g}}, \mathrm{A}_{1 \mathrm{~g}}$, and $\mathrm{B}_{2 \mathrm{~g}}$ modes of $\mathrm{RuO}_{2}$ are located at about 523, 645, and $710 \mathrm{~cm}^{-1}$, respectively [17]. This Raman analyses confirm that the $\mathrm{RuO}_{2} \cdot x \mathrm{H}_{2} \mathrm{O}$ thin films become dehydrated and 


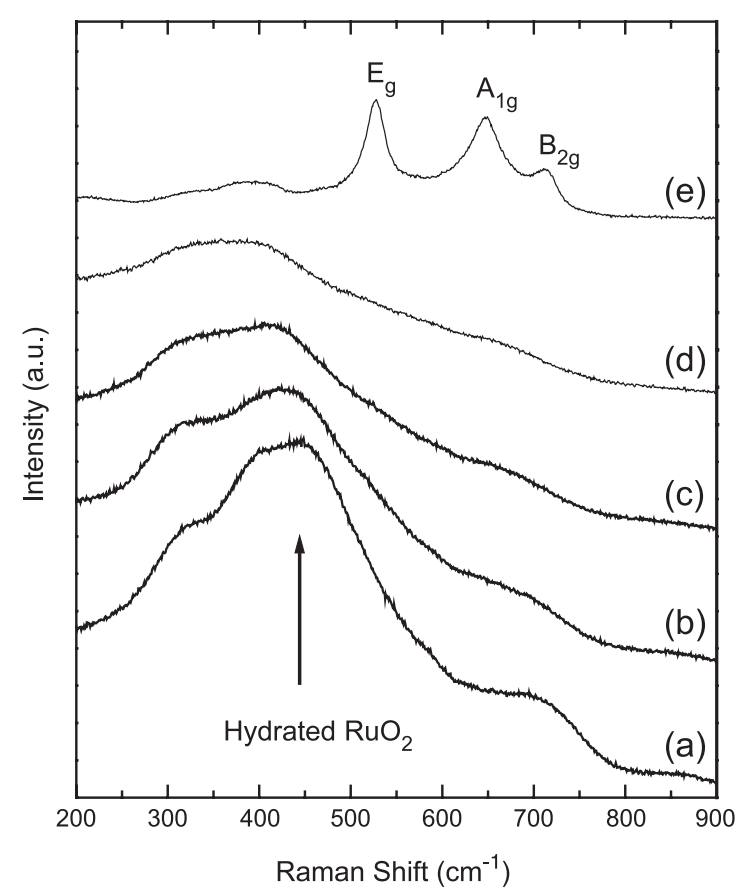

Fig. 7. Raman spectra of the $\mathrm{RuO}_{2} \cdot x \mathrm{H}_{2} \mathrm{O}$ thin films annealed at different temperatures of $25,100,150,200$ and $300{ }^{\circ} \mathrm{C}$.

begin to lose their optical modulation with increasing annealing temperature. The important point is that the hydrated form of the ruthenium oxide appears to be responsible for the optical modulation.

\section{Conclusion}

Amorphous hydrous ruthenium oxide thin films have been prepared by cyclic voltammetry films on ITO coated glass substrates from aqueous ruthenium chloride solutions. The cyclic voltammograms exhibits proof of capacitive behavior and also show two redox reaction peaks in each cathodic and anodic scan. The as-deposited $\mathrm{RuO}_{2} \cdot x \mathrm{H}_{2} \mathrm{O}$ thin films exhibit a $50 \%$ modulation of optical transmittance at 670 wavelength with capacitor charge/discharge in an anodic coloring fashion. The amorphous hydrous ruthenium oxide thin film has been demonstrated to be an excellent optical modulating material as well as an electrochemical supercapacitor. Our results indicate that the hydrated ruthenium oxide form appears to be responsible for the optical modulation of the ruthenium oxide thin film electrodes.

\section{Acknowledgements}

The authors acknowledge support from the DDRD program at the National Renewable Energy Laboratory, which is funded by the US Department of Energy, under Contract No. DE-AC-36-99GO10337. The work at Sogang was supported by Korea Research Foundation Grant (KRF-2000-015-DP0135).

\section{References}

[1] M. Ishikawa, M. Morita, M. Ihara, Y. Matsuda, J. Electrochem. Soc. 141 (1994) 1730.

[2] S.T. Mayer, R.W. Pekala, J.L. Kaschmitter, J. Electrochem. Soc. 140 (1993) 446.

[3] B. Pillay, J. Newman, J. Electrochem. Soc. 143 (1996) 1806.

[4] J.P. Zheng, T.R. Jow, J. Electrochem. Soc. 142 (1995) L6.

[5] J.P. Zheng, P.J. Cygan, T.R. Jow, J. Electrochem. Soc. 142 (1995) 2699.

[6] A.A.F. Grupioni, T.A.F. Lassali, J. Electrochem. Soc. 148-9 (2001) A1015.

[7] S.K. Deb, Appl. Opt. Suppl. 3 (1969) 192; Philos. Mag. 27 (1973) 801.

[8] C.G. Granqvist, Handbook of Inorganic Electrochromic Materials, vol. 5, Elsevier, New York, 1995.

[9] S.-H. Lee, H.M. Cheong, J.-G. Zhang, A. Mascarenhas, D.K. Benson, S.K. Deb, Appl. Phys. Lett. 74-2 (1999) 242.

[10] S.-H. Lee, H.M. Cheong, J.-G. Zhang, C. Edwin Tracy, A. Mascarenhas, D.K. Benson, S.K. Deb, Electrochim. Acta 44 (1999) 3111.

[11] S.-H. Lee, H.M. Cheong, C.E. Tracy, A. Mascarenhas, A.W. Czanderna, S.K. Deb, Appl. Phys. Lett. 7511 (1999) 1541.

[12] A.W. Czanderna, D.K. Benson, G.J. Jorgensen, J.-G. Zhang, C.E. Tracy, S.K. Deb, Solar Energy Mater. Solar Cells 56 (1999) 419.

[13] C.E. Tracy, J.-G. Zhang, D.K. Benson, A.W. Czanderna, S.K. Deb, Electrochim. Acta 44 (1999) 3195.

[14] S.-H. Lee, C.E. Tracy, J.R. Pitts, G. Jorgensen, S.K. Deb, Electrochim. Acta 46 (2001) 2237.

[15] C.-C. Hu, Y.-H. Huang, J. Electrochem. Soc. 146-7 (1999) 2465.

[16] S. Bhaskar, P.S. Dobal, S.B. Majumder, R.S. Katiyar, J. Appl. Phys. 89 (2001) 2987.

[17] S.Y. Mar, C.S. Chen, Y.S. Huang, K.K. Tiong, Appl. Surf. Sci. 90 (1995) 497. 